\title{
DESIGN, ENGAJAMENTO \& TRANSFORMAÇÃO: EXPOSIÇÃO INTERATIVA PARA A REDUÇÃO DE CESARIANAS DESNECESSÁRIAS E DA PREMATURIDADE IATROGÊNICA NO BRASIL
}

Rejane Spitz

Departamento de Artes \& Design

Pontifícia Universidade Católica do Rio de Janeiro

rejane@puc-rio.br

Resumo: Este artigo apresenta o projeto "Sentidos do Nascer", uma exposição interativa e itinerante, que tem por objetivo a valorização do parto normal e nascimento, de forma a influenciar na modificação da cultura e contribuir para a redução da cesariana desnecessária e da prematuridade iatrogênica no Brasil. O cenário do excesso de cesariana no Brasil envolve uma complexa relação histórica, ética, política, econômica e sociocultural, que passa pela institucionalização do parto e relações de dominação da ciência, além da representação da cesariana na sociedade como procedimento seguro, rápido e sem dor. Do total dos nascimentos no Brasil em 2013, 56,7\% foram por meio de cesáreas, e nos hospitais privados a proporção chegou a $80-90 \%$, sendo a maioria de cesarianas eletivas sem indicação, com forte influência médica sobre a decisão da via de parto ao longo do pré-natal. Nesse cenário, há necessidade de melhor compreensão do imaginário social sobre o parto e nascimento, e de ações efetivas para reverter esta tendência, e foram esses os objetivos principais do projeto "Sentidos do Nascer". Durante seu percurso na exposição, os visitantes se identificam com as temáticas do parto e nascimento apresentadas por meio de elementos lúdicos e interativos, que provocam sensações, experiências e reflexões - tornando-se, assim, protagonistas da transformação. Aspectos referentes à concepção, desenvolvimento e resultados da exibição são apresentados e discutidos sob a ótica do Design, sublinhando-se seu potencial para promoção da educação, conscientização e mudança de comportamento da população em relação ao parto normal e à cesariana.

Palavras-chave: design, interatividade, narrativa, parto, nascimento

Abstract: This article presents the project "Sentidos do Nascer", an interactive, itinerant exhibition, aimed at the enhancement of normal labor and delivery, in order to influence cultural change and contribute to reducing unnecessary caesarean section and iatrogenic preterm births in Brazil. The scenario of excess cesarean section in Brazil involves a complex historical, ethical, political, economic and socio-cultural relationship that has to do with the institutionalization of labor and relations of science 
domination, in addition to the C-section perception and representation in our society as a safe, quick and painless procedure. In private hospitals the proportion of caesarean reaches $80-90 \%$, most elective cesareans without indication, with strong medical influence on the decision of the mode of delivery during the prenatal period. In this scenario, there is need for better understanding of the social imaginary of labor and birth, and effective action to reverse this trend, and those were the main goals of the project "Sentidos do Nascer". During their journey in the exhibition, visitors identify with the themes of labor and birth - presented through playful and interactive elements, which cause sensations, experiences and reflections and become the protagonists of transformation. Aspects related to the creation, development and results are presented and discussed from the perspective of design, underlining its potential for promoting education, awareness and behavior change towards normal delivery and cesarean section.

Keywords: design, interactivity, narrative, childbirth, birth.

\section{INTRODUÇÃO: PARTO E NASCIMENTO NO BRASIL}

O trabalho de parto tem imenso valor, pois prepara o bebê para a transição neonatal e finaliza sua maturação fina. Os benefícios de um processo normal do nascimento são inegáveis, e ainda assim, grande parte da ultima geração de brasileiros perdeu este precioso bem. O Brasil é o campeão de cesáreas desnecessárias do mundo, o que vem repercutindo com o aumento da prematuridade e outros efeitos adversos sobre a saúde da mulher e do bebê. Do total dos nascimentos no Brasil em 2013, 56,7\% foram por meio de cesáreas. Quando considerados apenas os hospitais privados, essa proporção chega a $80-90 \%$, a maioria de cesarianas eletivas sem indicação, com forte influência médica sobre a decisão da via de parto ao longo do prénatal. Pesquisa conduzida por Dias et al (2008) com 437 parturientes no Estado do Rio de Janeiro constatou que embora $70 \%$ das mulheres não relatassem preferência inicial pela cesariana, $90 \%$ apresentaram esse tipo de parto. Os resultados da investigação indicaram que, independente do desejo inicial da gestante, a interação com o serviço de saúde resultou na cesariana como via final de parto (Dias et al, 2008).

$O$ peso insuficiente e a imaturidade quando a cirurgia é programada sem respeitar o desenvolvimento pleno do bebê, os problemas respiratórios e a sua internação em UTI neonatal são algumas das graves consequências dessa situação. Há ainda maior risco de problemas de saúde na infância e na vida adulta, como a obesidade, diabetes, hipertensão, asma, alergias, outras doenças imunológicas e até o autismo. Hemorragias, infecção, complicações anestésicas e maior risco na próxima gravidez são algumas das graves consequências para a saúde da mulher (Spitz et al, 2015).

A pressa do mundo contemporâneo contaminou a forma de nascer. Além de interesses comerciais do sistema privado de saúde, essas práticas são reforçadas pela cultura do consumo e da praticidade que atualmente domina a sociedade, que organiza o tempo em função da produção. As gestantes são levadas a uma cirurgia desnecessária, e com pouca informação e condição para participação ativa nessa 
decisão, na maioria das vezes, definida pelo profissional, numa relação muito desigual de poder.

Assim, esse cenário envolve uma complexa relação histórica, ética, política, econômica e sociocultural, que passa pela institucionalização do parto, pelos processos de mercantilização e medicalização da vida - marca de status social da sociedade de consumo - relações de dominação da ciência, da medicina e de gênero, além da representação da cesariana na sociedade como procedimento seguro, rápido, conveniente, limpo e sem dor. Retirar o bebê por meio de uma cirurgia programada antes do trabalho de parto e sem indicação pode resultar em um bebê prematuro (antes de 37 semanas) ou imaturo (o bebê é retirado antes de seu pleno desenvolvimento), o que aumenta os riscos à sua saúde e o desenvolvimento neuropsico-afetivo. Acelerar o parto também tem consequências. A ocitocina artificial que se usa com este fim pode provocar dor e diminuir a oxigenação para o bebê. Comumente se diz que o bebê sofre no parto normal, mas muitas vezes isto decorre das intervenções desnecessárias e não pelo parto em si. Sofrimento para a mãe e para o bebê quando não se respeita a normalidade do processo. Aliado a isso está o fato de a assistência ao parto ter se tornado muito invasiva e agressiva. Frequentemente, são utilizados procedimentos sem embasamento científico, transformando o cenário do parto e nascimento em um momento de sofrimento e horror. Reforçam, assim, representações sociais do parto como uma doença e o corpo feminino como incapaz (BRASIL/MINISTÉRIO DA SAUDE, 2015; SPITZ et al, 2015).

Nas últimas décadas, uma série de iniciativas da sociedade civil organizada e das políticas públicas vem buscando reverter esse quadro com a disseminação de informação adequada e promoção da assistência humanizada ao parto e nascimento. Mobilizam a sociedade e o sistema de saúde para a mudança do modelo de atenção obstétrica e neonatal, e garantia dos direitos da mulher e da criança a uma assistência respeitosa e digna, que proteja e promova a saúde e o afeto.

Com este objetivo surgiu o projeto "Sentidos do Nascer" - fruto da parceria entre a Universidade Federal de Minas Gerais (UFMG), Sistema Único de Saúde (SUS) e a Pontifícia Universidade Católica do Rio de Janeiro (PUC-Rio), com patrocínio da Bill \& Melinda Gates Foundation e das agências CNPq e Fapemig - visando ampliar o debate sobre questões relacionadas ao nascimento no Brasil.

\section{2. "SENTIDOS DO NASCER": UMA EXPOSIÇÃO INTERATIVA E ITINERANTE}

O projeto "Sentidos do Nascer" caracteriza-se como uma pesquisa de intervenção. Seu objetivo é analisar os efeitos de uma exposição que valoriza o parto normal, como estratégia para redução da cesariana desnecessária e da prematuridade iatrogênica no Brasil. A partir da conjugação de visões interdisciplinares, a conceituação e o desenvolvimento do projeto foram fundamentados na hipótese de que uma exposição itinerante e interativa (com territórios ampliados por redes sociais, experimentação de novas linguagens e recursos comunicacionais) permite intensificar o diálogo com o público, seu repertório, experiências e referências culturais, suscitando sensações, emoções e transformação da sua percepção, e, desta forma, pode contribuir para a mudança de comportamento da população em relação ao parto normal e à cesariana.

Por se tratar de uma equipe numerosa, envolvendo cerca de 20 profissionais das áreas de Educação, Saúde e Design, buscou-se conceituar o projeto de forma a que 
as subequipes pudessem trabalhar de forma integrada. Para isso, nos meses iniciais do projeto, foram realizadas longas e frutíferas reuniões reunindo todos os membros da equipe - oriundos das cidades do Rio de Janeiro, Belo Horizonte, São Paulo e Brasília. A equipe de Design teve, assim, a oportunidade de conviver com os demais membros do projeto - educadores, pediatras, obstetras, doulas, enfermeiras, arquitetos - e, em conjunto, discutir suas bases conceituais e seu briefing.

\subsection{Conceituação e briefing}

Um dos conceitos iniciais básicos estabelecidos para o projeto dizia respeito ao partido que seria adotado para a criação da ambientação da exposição. Além do seu caráter itinerante - o que demandaria facilidade de transporte e montagem - os demais membros e coordenadores do projeto explicitaram seu desejo de que a exposição tivesse a preponderância da abordagem sensorial sobre a racional, que a vivência fosse priorizada mais do que a informação lógica, sempre com um caráter preponderantemente lúdico, de forma a motivar a participação do público que circularia pelos locais onde seria exibida a exposição.

Foi identificado também que o contexto cultural do tema deste projeto diferenciava-se muito de outras campanhas de saúde, tais como as relativas à AIDS e ao tabagismo - estudos prévios desenvolvidos pelos coordenadores da equipe de Design (GAMBA Jr., 2006; SPITZ \& GAMBA Jr., 2007; SZKLO et al, 2009; VOLCHAN et al, 2009; NASCIMENTO et al, 2010). No caso da temática do projeto "Sentidos do Nascer" fazia-se necessário um grande esforço de aproximação do público em relação ao tema, pouco conhecido e raramente debatido pela população em geral.

Em relação aos conteúdos, além de abordar e divulgar a produção de conhecimento e a reflexão atual sobre as evidências científicas e experiências concretas de utilização da tecnologia apropriada para atenção ao parto e nascimento, a exposição deveria também fornecer elementos para o desenvolvimento de um olhar crítico do visitante em relação ao cenário da hipermedicalização do parto, da perda do protagonismo da mulher e da exploração do parto como um negócio. O projeto teria como perspectiva a "implicação dos sujeitos" nas narrativas e conteúdos da exposição, de forma a permitir múltiplas experiências sensoriais, cognitivas e estéticas.

Nessa direção, a proposta expositiva teve como uma de suas diretrizes a criação de um ambiente imersivo que envolvesse os visitantes nas discussões, conceitos e perspectivas apresentados. O partido adotado - de interatividade, imersão e dinamismo - atenderia a todos os visitantes, em qualquer faixa etária ou nível educacional, desde que se mantivesse um nível de simplicidade e organicidade nas interfaces de interação que seriam criadas para o projeto.

Uma das definições adicionais do briefing referia-se ao tempo de permanência do visitante na exposição. A opção escolhida foi a de permitir que o visitante pudesse fazer uma visita rápida pelas áreas da exposição, aproveitando sua eventual disponibilidade temporária (por exemplo, seu horário de almoço no trabalho) e que depois pudesse retornar para uma visita mais completa, caso houvesse interesse em adquirir informações mais detalhadas sobre a temática apresentada.

Em síntese, os itens conceituais que nortearam o desenvolvimento deste projeto foram:

- Temática: valorizar o parto normal, como estratégia para redução da cesariana desnecessária e da prematuridade iatrogênica no Brasil. 
- Abordagem: múltiplas experiências sensoriais, cognitivas e estéticas, reunindo diferentes perspectivas, apresentando controvérsias que suscitam questionamentos. Caráter lúdico e possibilidade de visitas curtas ou mais demoradas, dependendo do grau de interesse do visitante pela temática.

- Locais de exibição: espaços públicos de ampla circulação em 3 grandes capitais brasileiras (Belo Horizonte/MG, Rio de Janeiro/RJ e Brasília/DF).

- Caráter itinerante da exposição: com facilidade de transporte e montagem;

- Público-alvo: a sociedade em geral, em particular mulheres, gestantes, estudantes do ensino médio e ensino superior, professores, gestores e, em especial, profissionais de saúde, com visitação estimada em 30 mil pessoas num período de 12 meses.

\subsection{Criação e desenvolvimento}

A concepção do espaço buscou soluções inovadoras para a criação de um cenário expositivo instigante e imersivo, com facilidade de transporte e montagem, conjugando arte, design, ciência e tecnologia. Através de estudos sobre a temática e diagnóstico comunicacional do conteúdo, pesquisa de similares existentes, brainstorming e processos de geração de ideias, categorização das possibilidades, desenvolvimento de esboços e de protótipos em 2D e em 3D (analógicos e digitais), bem como experimentações e testagens, foram geradas pela equipe de Design as alternativas finais para a estruturação, definição de percurso e navegação, e detalhamento de todos os elementos constituintes da exposição.

A solução de espaço físico da exposição proposta pela equipe de Design contemplou questões relativas à visibilidade, atratividade, unidade visual e coesão, além de consonância com a temática tratada.

Para facilitar a montagem e transporte de uma exposição itinerante que ocuparia espaços públicos de ampla circulação, foram utilizados 4 containers, cada um com área de $24 \mathrm{~m}^{2}$, estrutura resistente e custo reduzido, que permitiram fácil adaptação e modularidade. Tais containers, montados em forma de " $U$ ", foram totalmente cobertos por um toldo que é sustentado por uma haste principal, de forma a criar uma elevação central. O toldo traz como beneficio não apenas a proteção superior, mas ainda a criação de um espaço central adicional coberto, entre os containers (Figuras 1 e 2).
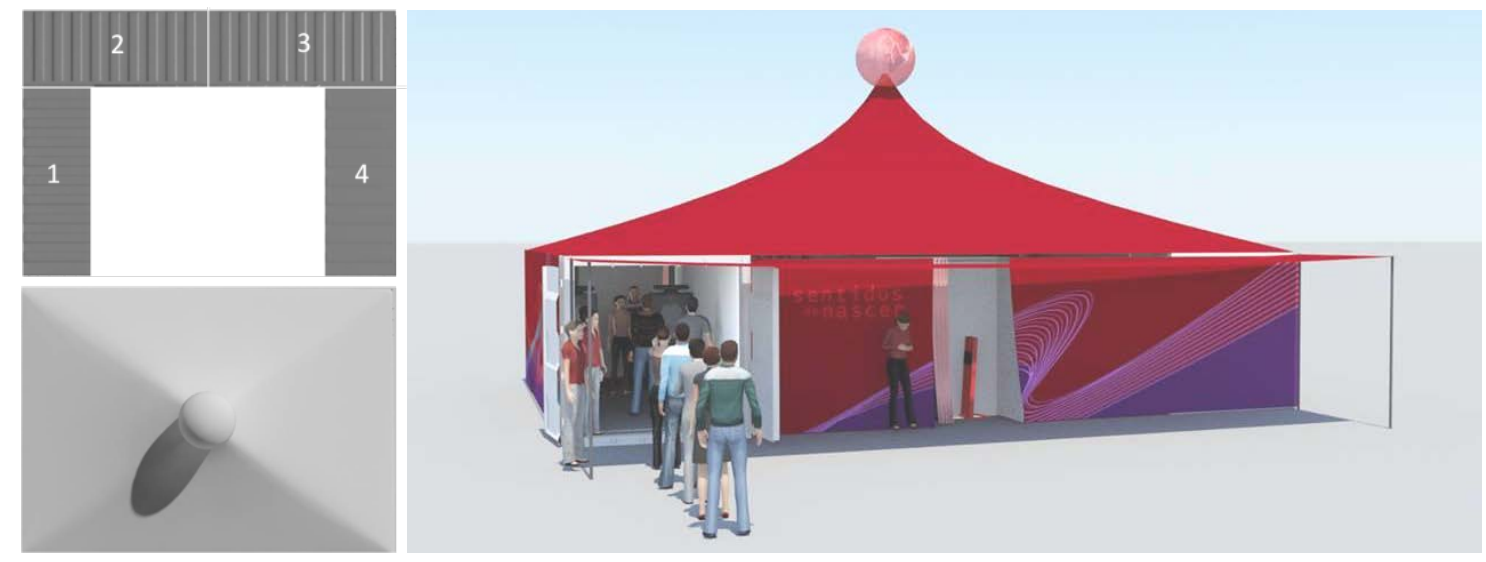

Figura 1 - projeto da estrutura da exposição "Sentidos do Nascer"

(elaborada pelo autor, com base na pesquisa realizada) 


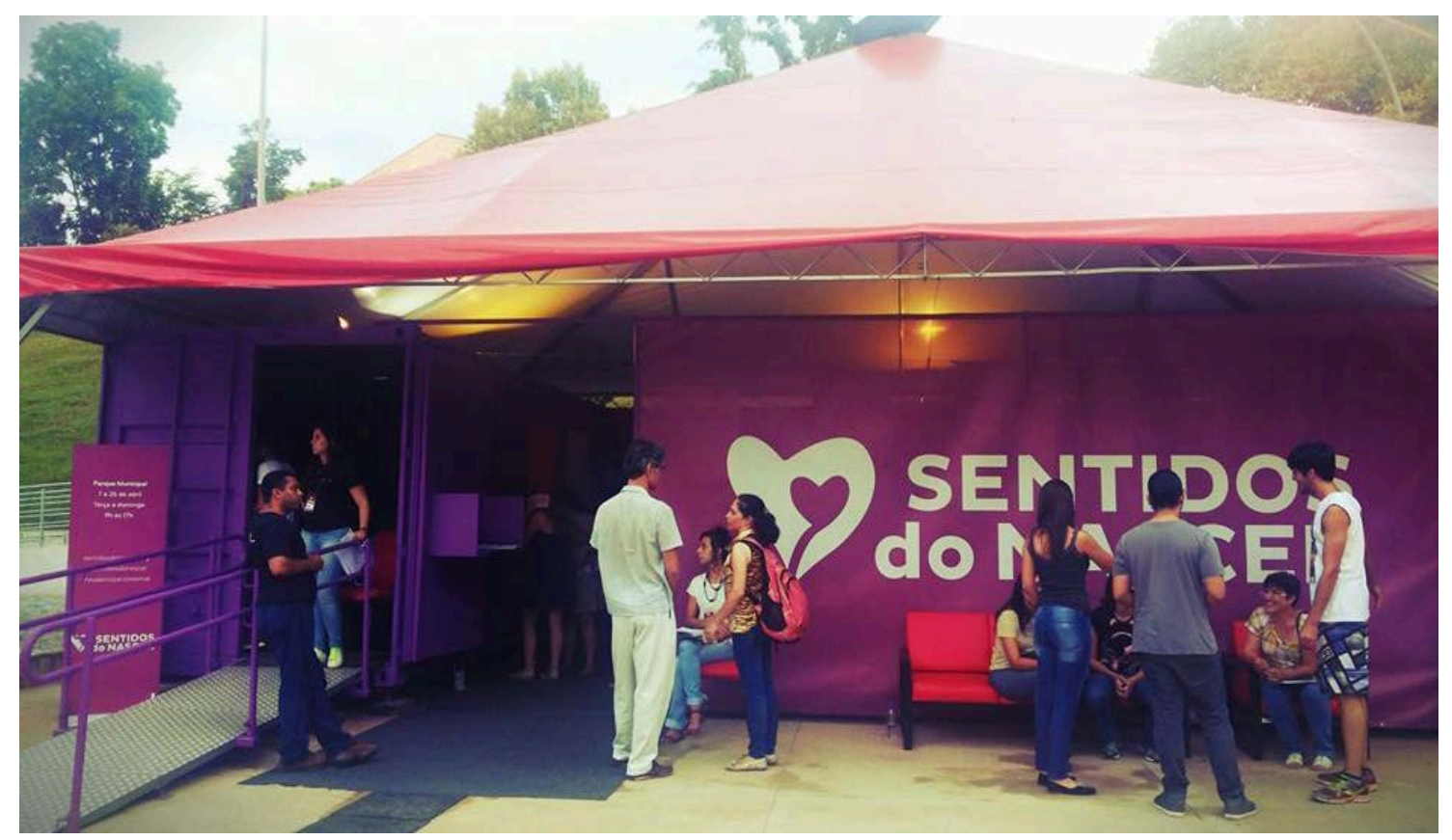

Figura 2 - estrutura final da exposição "Sentidos do Nascer"

(elaborada pelo autor, com base na pesquisa realizada)

A partir de conteúdos e informações fornecidos pelos demais membros da equipe do projeto, a parte interna da exposição foi desenvolvida pela equipe de Design de forma a suscitar as seguintes experiências nos visitantes:

- Estímulo à reflexão sobre o nascer;

- Simulação lúdica da experiência da gestação e espaço para compartilhamento das imagens por rede social;

- Apresentação da multiplicidade de pontos de vista e relativização do senso comum sobre o nascimento;

- Vivência sensorial da experiência do nascer;

- Acesso à informação audiovisual e aprofundamento das questões levantadas;

- Espaço para compartilhamento de depoimentos;

- Questionário interativo sem mediador para conclusão da pesquisa (posterior à visitação da exposição);

Essas experiências foram desenvolvidas para serem vivenciadas pelos visitantes através de um percurso sequencial pré-determinado, perpassando quatro ambientes principais:

$1^{\circ}$ Ambiente - Gestação: o objetivo deste primeiro ambiente é criar uma simulação lúdica da experiência da gestação, simular a sensação de "se ver e se sentir grávido(a)", e fomentar o compartilhamento de fotos dos visitantes "grávidos" por rede social. Concebemos uma instalação interativa para este primeiro espaço da exposição, de modo a criar uma experiência lúdica, simples, amigável e surpreendente, criando uma espécie de "sala de espelhos". Por meio da instalação de dispositivos interativos que capturam a imagem do visitante, reconhecendo a estrutura de seu 
esqueleto, o visitante vê a sua imagem num monitor acrescida de uma barriga de gravidez (simulando gestação em fase avançada), além de seios inchados (tal como costuma ocorrer durante a gravidez) e de um feto (de tamanho correspondente à gestação em fase avançada). À medida que o visitante se movimenta, esses elementos da simulação acompanham seu movimento, ficando sobrepostos à imagem em qualquer posição que o visitante assuma, de frente ou de lado. O sistema automaticamente captura imagens dos visitantes "grávidos" (dando-Ihes 3 segundos para fazerem uma pose), imagem essa que é enviada a um banco de dados, e também postada na pagina do Facebook do projeto "Sentidos do Nascer", podendo ser compartilhada pelos visitantes em suas próprias paginas individuais (Figuras 3 e 4).
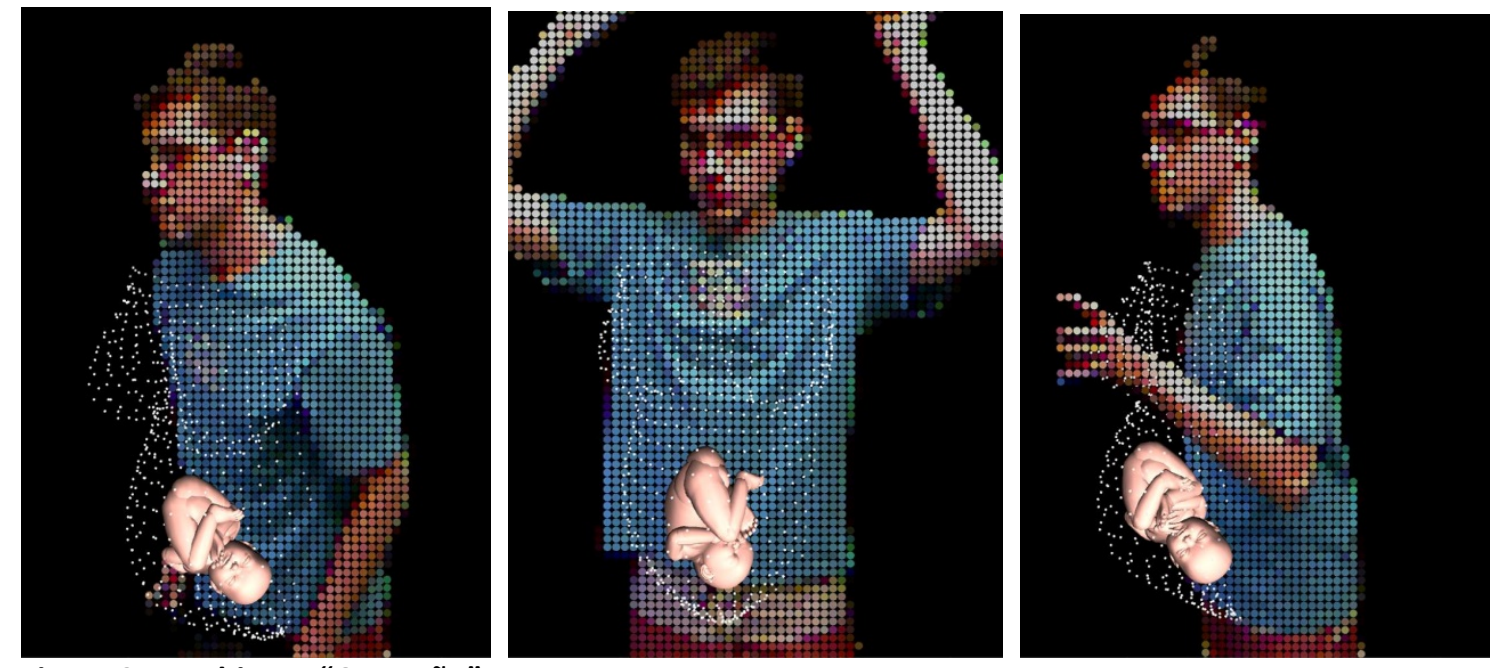

Figura 3 - Ambiente "Gestação" - testagem

(elaborada pelo autor, com base na pesquisa realizada)
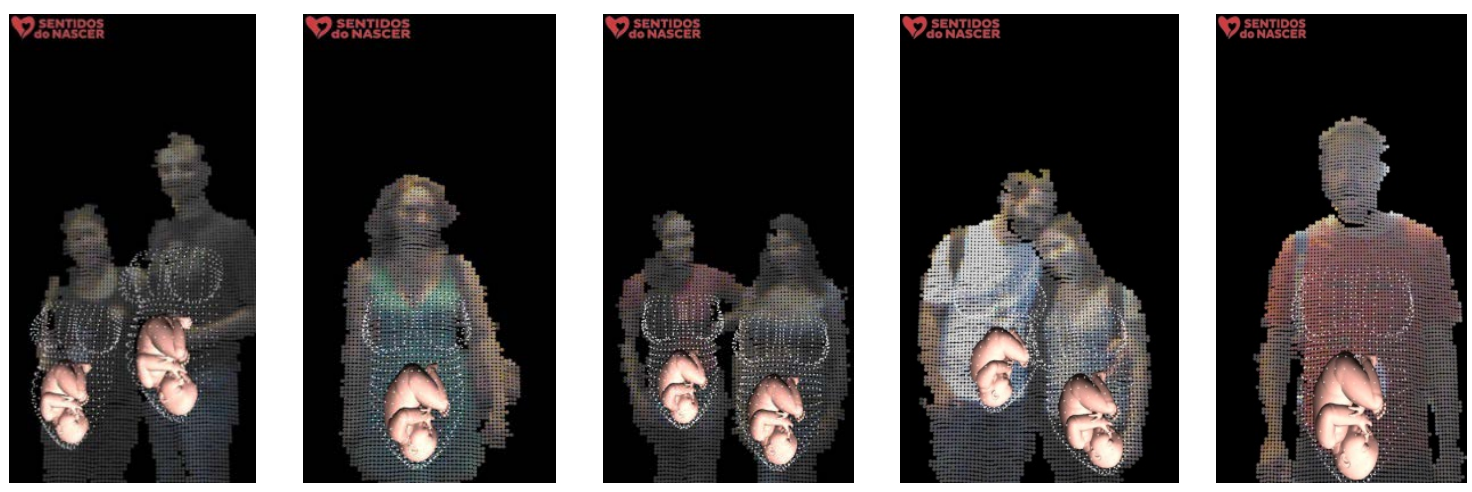

Figura 4 - Ambiente "Gestação" - fotos de visitantes "grávidos", publicadas diretamente na pagina do projeto "Sentidos do Nascer" no Facebook (elaborada pelo autor, com base na pesquisa realizada)

2ㅇ Ambiente - Diálogos: para a apresentação da multiplicidade de pontos de vista e relativização do senso comum sobre o parto e o nascimento, este ambiente apresenta monitores suspensos, num formato semi-circular, onde atores caracterizados como obstetras, enfermeira, doula, parturiente, mãe, avó, amiga e marido da parturiente se comunicam entre si, e com o visitante. Tais diálogos sublinham aspectos contraditórios sobre o parto e o nascimento, ora tratando de aspectos da cesariana (necessária ou desnecessária), ora explicitando as vantagens para a mãe e para o bebê da opção pelo parto vaginal (Figura 5). 

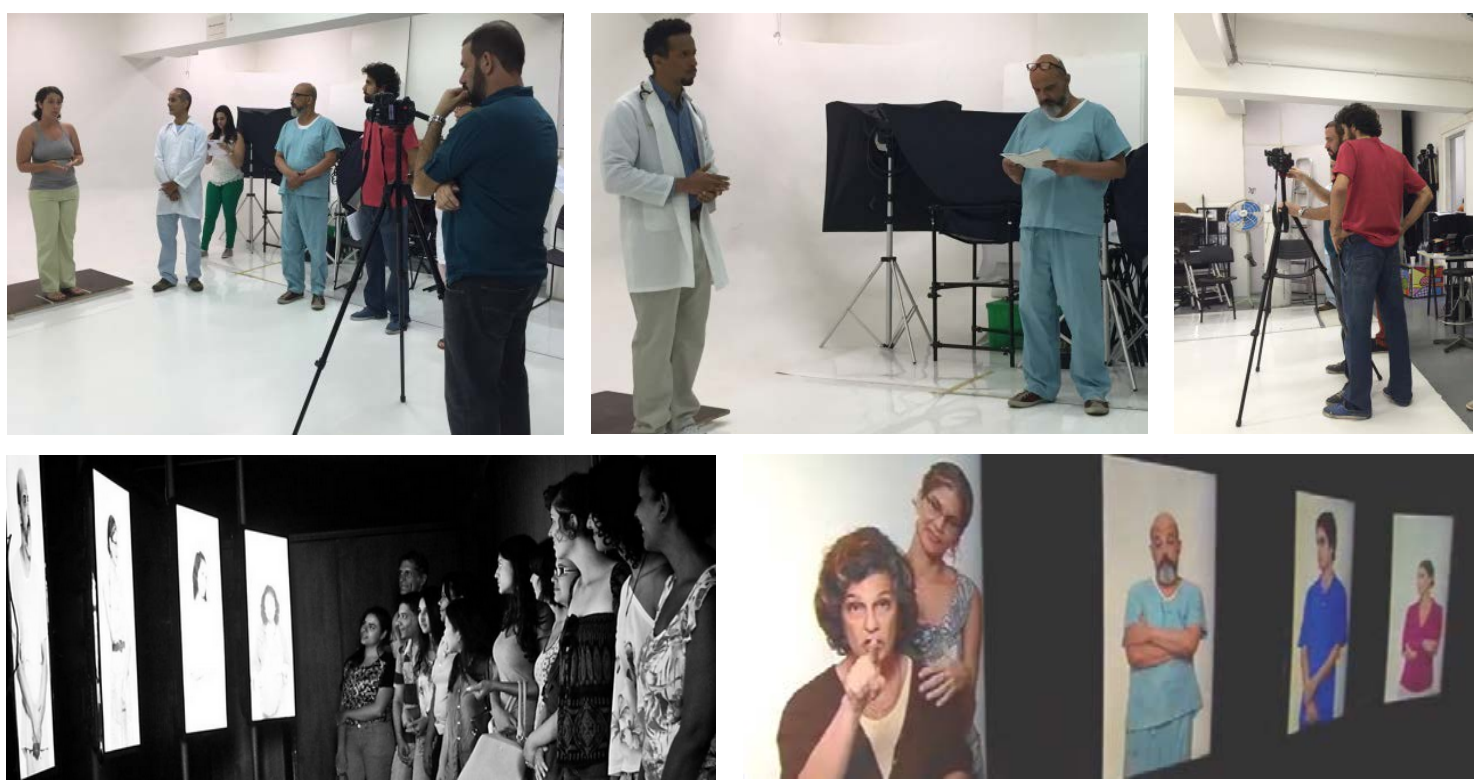

Figura 5 - Ambiente "Diálogos"

(elaborada pelo autor, com base na pesquisa realizada)

$3^{\circ}$ Ambiente - Nascimento: esta área tem por objetivo criar uma vivência sensorial da experiência do nascer. $O$ visitante entra num compartimento onde vive uma experiência imersiva de estar nascendo como num parto humanizado. Ele atravessa um estreito e comprido túnel, feito de tecido, macio, aquecido, aconchegante e flexível, simulando o processo de nascimento de um bebê por parto vaginal. Esse túnel (Figura 6) tem iluminação e sons, reforçando aspectos positivos do parto humanizado.
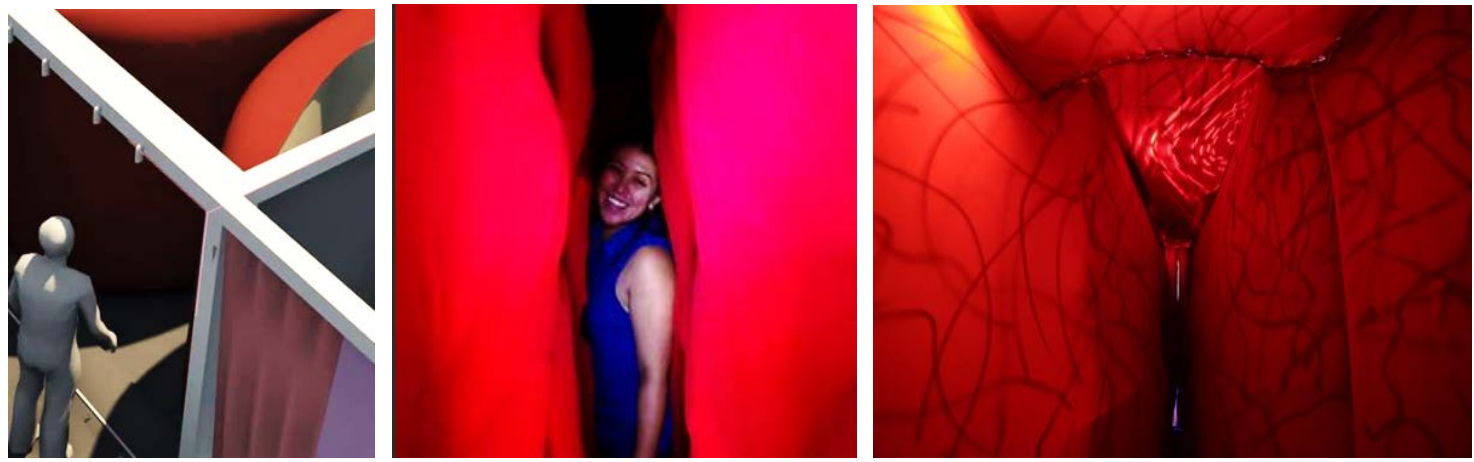

Figura 6 - Ambiente "Nascimento"

(elaborada pelo autor, com base na pesquisa realizada)

40 Ambiente - Convivência: área com múltiplas funções, tais como acesso à informação impressa e audiovisual, aprofundamento das questões levantadas durante a visita, palestras, debates e apresentações de curta duração (Figura 7). Nesse espaço são realizadas ainda as entrevistas (questionário) dos mediadores com $5 \%$ dos visitantes, há espaço para gravação de depoimentos por parte dos visitantes, e espaço para respostas ao questionário final (totem eletrônico). 

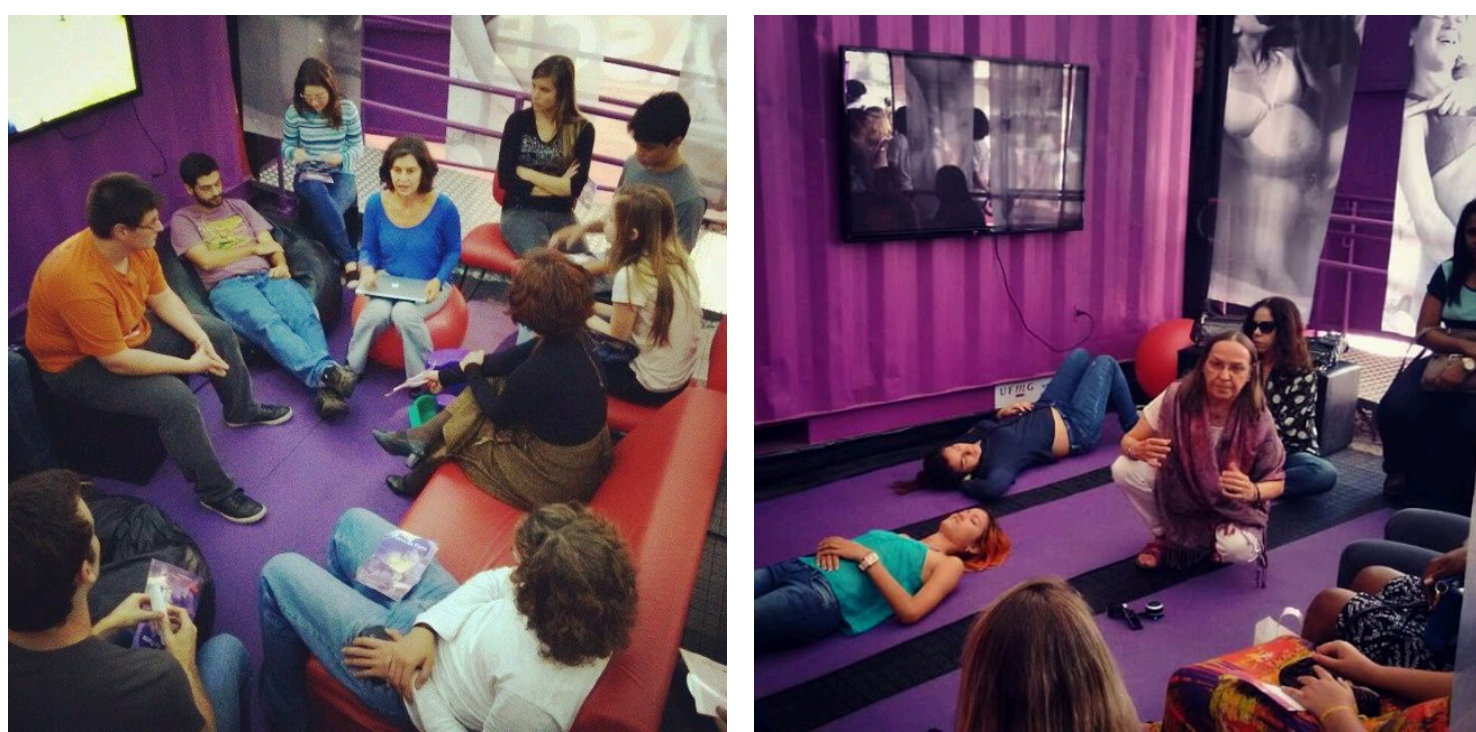

Figura 7 - Ambiente "Convivência" - espaço de informação, palestras, debates e aulas

(elaborada pelo autor, com base na pesquisa realizada)

\section{CONCLUSÃO}

O Design tem papel fundamental no que se refere à educação e conscientização da população a respeito de temáticas nas áreas de prevenção e saúde, podendo ajudar a promover transformações culturais e mudanças sociais. Em nossa atuação, nos últimos anos, como designers trabalhando em parceria com profissionais das áreas de saúde, temos verificado a necessidade de utilização de abordagens inovadoras que permitam conscientizar e engajar a população brasileira em ações para a promoção da saúde, e de prevenção e combate a doenças (NASCIMENTO et al, 2010; SZKLO et al, 2009; VOLCHAN et al, 2009).

Diante da amplitude dos objetivos a serem alcançados - considerando-se a escala dos projetos e campanhas de abrangência nacional nas áreas de prevenção e saúde no Brasil - são necessárias novas estratégias de comunicação para disseminar e divulgar a informação, estimular a reflexão da sociedade e acelerar as mudanças de comportamentos desejadas.

Esse foi o caso deste projeto, em que coube à área de Design a tarefa de criar um espaço de sensibilização, reflexão e aquisição de conhecimentos sobre o parto e o nascimento, de forma a atingir a totalidade da população brasileira. Com a intenção de buscar a "implicação dos sujeitos" nas narrativas e conteúdos da exposição, os elementos lúdicos com os quais o visitante interage durante o percurso vão muito além da simples transmissão de informações, envolvendo e engajando o sujeito, de forma a fazê-lo refletir a respeito das questões apresentadas e a provocar a ressignificação do parto e do nascimento (BRASIL/MINISTÉRIO DA SAUDE, 2015). Conceitos como envolvimento, engajamento, estranhamento e motivação - aqui entendidos como variáveis projetuais - possibilitam novas abordagens de diálogo com o público, bem como melhor absorção e retenção da informação apresentada (NEVES \& SPITZ, 2005). Neste caso, tanto a qualidade interativa dos elementos da exposição bem como seu caráter lúdico fazem com que a informação não apenas se coloque à disposição do visitante, mas, sobretudo, provoque seu engajamento e sua atuação. A exposição tem seus territórios ampliados ainda por redes sociais, o que permite 
promover e divulgar os eventos em pauta, disseminar informações complementares e intensificar o diálogo com o público, incluindo seu repertório, suas experiências, comentários e críticas, bem como suas referências culturais, o que acontece especialmente após sua visitação presencial à exposição, dando continuidade a tal experiência.

A exposição "Sentidos do Nascer" foi concebida de modo a ocupar espaços públicos de ampla circulação, visando atingir um número significativo de visitantes. Foi exibida em Belo Horizonte (Minas Gerais), no Rio de Janeiro e em Niterói (Rio de Janeiro), e também em Brasília (Distrito Federal), com participação estimada de 30 mil pessoas, durante um período de 12 meses. Em cada local, contou-se com o envolvimento dos pesquisadores das instituições participantes do projeto, além das parcerias locais comunitárias, governamentais e não governamentais. Entre os meses de março e agosto de 2015 a exposição recebeu 22.621 visitantes. 81,4\% eram mulheres e 582 eram gestantes, ou seja, o equivalente a $2,6 \%$ dos visitantes. A idade média dos visitantes foi de 31,6 anos, sendo que $53,6 \%$ deles tinham renda menor do que cinco salários mínimos e $51 \%$ tinham ensino superior completo.

Durante o funcionamento da exposição foram realizadas pesquisas de publico, com gestantes, grupos focais com população de interesse, repercussão na mídia e nas redes sociais. Os resultados da pesquisa revelaram que, ao se comparar os dois momentos antes e depois da exposição - pode-se observar uma importante modificação das opiniões dos visitantes sobre o parto normal. Após a visitação, 67,5\% relataram que "mudaram muito ou totalmente" sua visão sobre o parto normal e $60,1 \%$ falaram sobre sua mudança de percepção em relação à cesariana. Entre as gestantes, 56\% registraram substancial mudança de percepção sobre o parto normal e $76 \%$ relataram sua preferencia final pelo parto normal, conforme dados dos relatórios da pesquisa "Sentidos do Nascer".

Segundo os pesquisadores, o dado mais surpreendente - ainda que não tenha sido quantificado - foi o grande numero de pessoas que ficaram emocionadas durante a visitação, "saindo do canal do nascimento com lágrimas nos olhos", e que retornaram à exposição, alguns dias depois, trazendo seus familiares e amigos. Outro dado que mereceu destaque no relatório da pesquisa foi a grande repercussão da exposição nas redes sociais, na forma de fotos, textos, discussões e comentários compartilhados e divulgados nas mídias sociais (Brasil/Ministério da Saúde, 2015).

Em conclusão, ressalta-se que tais resultados positivos atestam a importância de iniciativas dessa natureza. A exposição interativa e itinerante "Sentidos do Nascer" continua sendo exibida em várias cidades brasileiras durante o ano de 2016, e em breve terá uma nova versão, em caráter permanente, a ser exibida pelo Ministério da Saúde em espaço próprio de exposição a ser criado na cidade do Rio de Janeiro. 0 projeto "Sentidos do Nascer" vem demonstrando ser uma eficaz iniciativa para influenciar e modificar a cultura de nossa população a respeito das temáticas do parto e do nascimento, contribuindo assim para a redução da cesariana desnecessária e da prematuridade iatrogênica no Brasil.

\section{AGRADECIMENTOS}

Nossos agradecimentos à Sônia Lansky (Secretaria Municipal de Saúde de Belo Horizonte) e Bernardo Jefferson de Oliveira (UFMG), coordenadores do projeto 
"Sentidos do Nascer", por nos ter convidado a coordenar os aspectos referentes ao Design. À Bill \& Melinda Gates Foundation, ao CNPq e ao Ministério da Saúde nosso agradecimento pelo financiamento do projeto, e ao Departamento de Artes \& Design da Pontifícia Universidade Católica do Rio de Janeiro pelo imenso apoio concedido. Agradecemos em especial a Nilton Gamba Jr. (LADEh/PUC-Rio) que, em parceria com a autora deste artigo, participou como coautor de todas as etapas de criação e elaboração dos aspectos referentes ao projeto de Design, e a Wesley Oliveira, Renan Kogut e Levy Fernandes (membros da equipe do LAE/PUC-Rio), por sua criatividade, conhecimento técnico e enorme disposição. Finalmente, nosso agradecimento a todos os demais profissionais - médicos, pediatras, enfermeiros, doulas, atores, diretores, editores e cenógrafos, dentre outros - que participaram do desenvolvimento deste trabalho.

\section{REFERÊNCIAS}

BRASIL. MINISTÉRIO DA SAUDE. Secretaria de Atenção à Saude. Departamento de Ações Programáticas Estratégicas. Sentidos do nascer: percepções sobre o parto e o nascimento. Catálogo. Brasília: Editora MS, Ministério da Saúde, 2015, 48 p.

DIAS, Marcos A. B. et al. Trajetória das mulheres na definição pelo parto cesáreo: estudo de caso em duas unidades do sistema de saúde suplementar do Estado do Rio de Janeiro. Ciência \& Saúde Coletiva. 2008, 13: P. 1521-1534.

GAMBA Jr., Nilton. Narrativa e AIDS. Noites Felinas e as dualidades da experiência narrativa pós-moderna. 2006. Tese (doutorado) - Pontifícia Universidade Católica do Rio de Janeiro, Curso de Pós-graduação em Psicologia Clínica.

NASCIMENTO, Bill E.M. et al. Neurociências, Artes Gráficas e Saúde Pública: Unindo Conhecimentos na Elaboração das Novas Advertências Sanitárias para Maços de Cigarros. História, Ciências, Saúde. Rio de Janeiro: Manguinhos, 2010, P. 243-252.

NEVES, Ana. C. Q. B. ; SPITZ, Rejane. Novos encantamentos: design, hipermídia e motivação. In: IX Congresso Iberoamericano de Gráfica Digital, SIGraDi 2005, Lima. IX Congresso Iberoamericano de Gráfica Digital, SIGraDi 2005, Lima: 2005. v. 01. P. 6974.

SPITZ, Rejane et al. Sentidos do Nascer: efeitos de uma exposição interativa na transformação da percepção sobre o parto e nascimento. In: MX Design Conference 2015, Cidade do México. MX Design Conference 2015 Proceedings. Cidade do México: Universidad Ibero Americana, 2015, v. 1, P. s/n.

SPITZ, Rejane e Gamba Jr., Nilton. Design \& campanhas anti-tabagismo: as novas imagens e advertências a serem impressas nos maços de cigarro no Brasil. In: 3으 Congresso Internacional de Design da Informação, 2007, Curitiba. Anais do 3o Congresso Internacional de Design da Informação. Curitiba: SBDI, 2007, v. 1. P. s/n.

SZKLO, André. S et al. Gains of stopping smoking: portraits of the dialogue between public health promotion, art and design. International Journal of Epidemiology, 2009, v. 38, P. $1459-1463$.

VOLCHAN, Eliane. et al. O impacto emocional das imagens de advertência em maços de cigarros. Ciência Hoje, 2009, v. 44, P. 32-37. 